\title{
IR spectroscopy of KBr salt and crystals
}

\author{
V.I. Goriletsky, A.I. Mitichkin, L.E. Belenko, T.P. Rebrova \\ STC «Institute for Single Crystals», National Academy of Science of Ukraine, Kharkiv
}

\begin{abstract}
The IR absorption spectra of the $\mathrm{KBr}$ salt pellets of different purity and crystals grown of them were investigated in the region of $400 \ldots 4000 \mathrm{~cm}^{-1}$. It was found that by the IR spectra of the $\mathrm{KBr}$ salt pellets suitable for growing optically pure crystals one can evaluate the $\mathrm{KBr}$ salt quality. Revealed in the IR spectra are not only the impurity oxygen-containing molecular anions and the adsorption water but also, indirectly through them, the most dominating cations of sodium, barium and calcium. Determined was the concentration, beginning from which sodium ions are observed in the IR spectra of the $\mathrm{KBr}$ salt pellets. The coefficient of proportionality between the concentration of sulfates in the $\mathrm{KBr}$ salt and the absorption coefficient of $\mathrm{SO}_{4}{ }^{2-}$ ions at the frequency of deformation vibration $v_{4}$ was found. The latter allows to estimate quantitatively the sulfates in the $\mathrm{KBr}$ salt.
\end{abstract}

Keywords: IR spectroscopy, express control, salt quality, absorption coefficient.

Paper received 04.11.00; revised manuscript received 05.01.01; accepted for publication 16.02.01.

\section{Introduction}

It is known that no absorption bands should be present in the IR spectra of $\mathrm{KBr}$ crystals. This is primarily achieved by a high degree of the $\mathrm{KBr}$ salt purity with respect to oxygen-containing molecular anions: $\mathrm{SO}_{4}{ }^{2-}, \mathrm{NO}_{3}{ }^{-}, \mathrm{NO}_{2}{ }^{-}$ etc. apart from this, the impurity polyvalent cations $\mathrm{M}^{2+}$ (where $M=\mathrm{Ca}, \mathrm{Ba}, \mathrm{Mg}, \mathrm{Pb}$ ) may form complexes $\mathrm{M}^{2+} \mathrm{SO}_{4}{ }^{2-}$ which are also revealed in the IR spectra of $\mathrm{KBr}$ pellets and crystals. Presence of large amounts of $\mathrm{Na}^{+}$ions worsens structural quality of $\mathrm{KBr}$ crystals.

Unlike nitrates and nitrites that can be eliminated by the overheating melt prior to crystal growth (Figs 1-2, 2-2) $\mathrm{SO}_{4}{ }^{2-}$ ions enter the crystal and, therefore, are considered to be the most harmful impurity. An attempt to evaluate the $\mathrm{KBr}$ salt quality by the IR spectra of $\mathrm{KBr}$ pellets (the salt suitable for obtaining optically pure crystals) was made in the present paper.

\section{Experimental}

The IR spectra of $\mathrm{KBr}$ pellets and crystals were measured on the spectrophotometers UR-20 and Specord M-82. $\mathrm{KBr}$ pellets of different purity grade were prepared by pressing the preliminarily ground salt at a pressure of
$6000 \mathrm{kgf} / \mathrm{cm}^{2} . \mathrm{KBr}$ crystals were grown by an open Kyropulos method. The observed in the IR spectra absorption bands were interpreted by the deformation and valence vibrations of molecular anions and their complexes with the polyvalent cations [1-4]. Concentration of $\mathrm{Na}^{+}$ions in the $\mathrm{KBr}$ salt was measured by the IR spectra of $\mathrm{KBr}$ pellets prepared in a humid atmosphere. Concentration of $\mathrm{Na}^{+}$ions in the model samples was determined by the method of flame photometry. For the determination of $\mathrm{SO}_{4}{ }^{2-}$ ion concentration in the $\mathrm{KBr}$ salt by the experimental data the authors calculated the coefficient of proportionality between concentration and absorption coefficient of $\mathrm{SO}_{4}{ }^{2-}$ ions at $615 \mathrm{~cm}^{-1}$ [5]. Concentration of sulfate-ions in the $\mathrm{KBr}$ salt was determined by the turbidimetry method [6].

\section{Results and discussion}

The results of the measurements of the IR spectra of $\mathrm{KBr}$ pellets and crystals are given in Figs 1-3. They confirm that the anionic impurities in the $\mathrm{KBr}$ salt are directly manifested in the IR spectra of pellets. The cations $\mathrm{Na}^{+}$, $\mathrm{Ba}^{2+}$ and $\mathrm{Ca}^{2+}$ which dominate among other impurity cations can be revealed indirectly as well, e.g. by structure variation of the absorption bands of $\mathrm{H}_{2} \mathrm{O}$ and $\mathrm{SO}_{4}{ }^{2-}$ ions. 


\section{V.I. Goriletsky et al.: IR spectroscopy of $\mathrm{KBr}$ salt and crystals}

Table. Crystallohydrates of alkali halide salts.

\begin{tabular}{ccccc}
\hline \hline Halogen & $\mathrm{F}$ & $\mathrm{Cl}$ & $\mathrm{Br}$ & $\mathrm{J}$ \\
\hline $\mathrm{Cs}$ & - & - & - & - \\
\hline $\mathrm{K}$ & $\mathrm{KF} \cdot 2 \mathrm{H}_{2} \mathrm{O}$ & - & - & - \\
\hline $\mathrm{Li}$ & - & $\mathrm{LiCl} \cdot 2 \mathrm{H}_{2} \mathrm{O}$ & - & - \\
\hline $\mathrm{Na}$ & - & - & $\mathrm{NaBr} \cdot 2 \mathrm{H}_{2} \mathrm{O}$ & $\begin{array}{c}\mathrm{NaI} \cdot 2 \mathrm{H}_{2} \mathrm{O} \\
\left(\mathrm{NaI} \cdot 5 \mathrm{H}_{2} \mathrm{O}\right)\end{array}$ \\
\hline
\end{tabular}

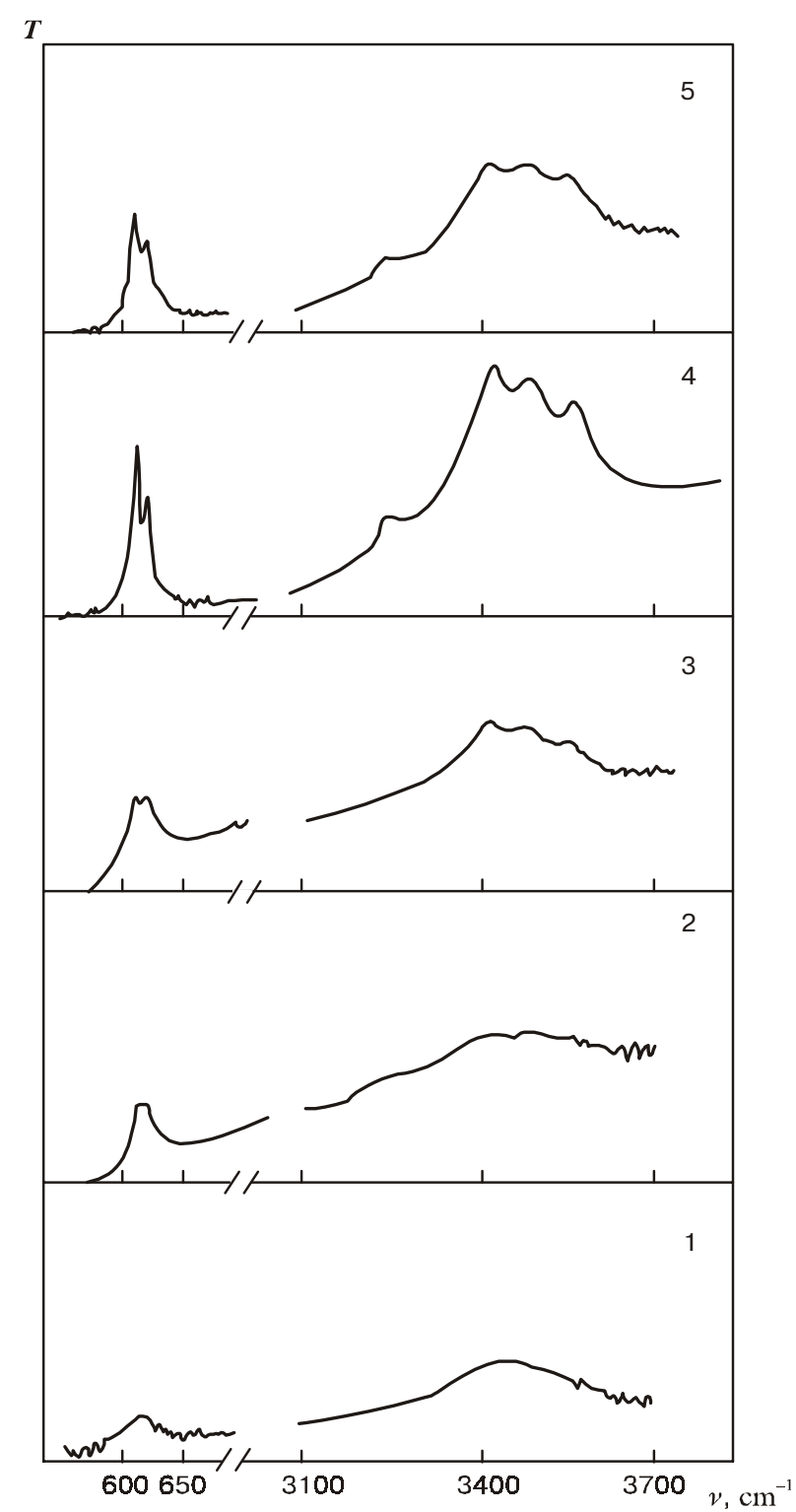

Fig. 1. IR spectra of different grade $\mathrm{KBr}$ pellets:

1 - ultra pure, 2, 3 - chemical pure, 4 - pure, 5 - salt after durable storage. Content of $\mathrm{M}^{2+}$ ions: 1 . $\mathrm{Ba}^{2+}-2 \cdot 10^{-4}, \mathrm{Ca}^{2+}-1 \cdot 10^{-4}$, $\mathrm{Mg}^{2+}-3 \cdot 10^{-5}, \mathrm{~Pb}^{2+} 1 \cdot 10^{-5}$ mass $\%$; 3. $\mathrm{Ba}^{2+}-1 \cdot 10^{-3}, \mathrm{Ca}^{2+}-2 \cdot 10^{-4}, \mathrm{Mg}^{2+}$ $5 \cdot 10^{-5}, \mathrm{~Pb}^{2+}-2 \cdot 10^{-5} \operatorname{mass} \%$.
As it is seen from Fig. 3 and the Table, sodium in the $\mathrm{KBr}$ salt can be rather clearly revealed at a concentration $\sim 9 \cdot 10^{-2}$ mass $\%$ by the IR spectra of $\mathrm{KBr}$ pellets $\sim 0.1 \mathrm{~cm}$ thick, the latter being prepared by grinding the salt in a humid atmosphere. This was promoted by the crystallohydrate $\mathrm{NaBr} \cdot 2 \mathrm{H}_{2} \mathrm{O}$ formation, its water giving two splitted absorption bands of valence and deformation vibrations $v_{2}$ and $v_{3}$ at 1630 and $3400 \mathrm{~cm}^{-1}$. Sulfateions in the IR spectra of the salt are observed by the absorption bands of $v_{3}\left(\mathrm{~F}_{2}\right)$ and $v_{4}\left(\mathrm{~F}_{2}\right)$ and at the presence of complexes $\mathrm{M}^{2+} \mathrm{SO}_{4}{ }^{2-}$, when the local symmetry of $\mathrm{SO}_{4}{ }^{2-}$ ions is lowered from $T_{d}$ to $C_{2 v}$, which leads to a splitting of $v_{3}\left(\mathrm{~F}_{2}\right)$ and $v_{4}\left(\mathrm{~F}_{2}\right)$ vibrations into three components and to the appearance of $v_{1}\left(\mathrm{~A}_{1}\right)$ vibration in the IR spectrum. Clear manifestation of the resolved structure of the absorption bands of sulfates depends on a quantitative ratio between $\mathrm{SO}_{4}{ }^{2-}$ and $\mathrm{M}^{2+}$ ions in $\mathrm{KBr}$ crystals (Figs 1, 2) and allows to interpret their availability. The coefficient of proportionality between $\mathrm{SO}_{4}{ }^{2-}$ ion concentration in the $\mathrm{KBr}$ salt and absorption coefficient of $\mathrm{SO}_{4}{ }^{2-}$ ions at the frequency of deformation vibrations at $615 \mathrm{~cm}^{-1}$ for a number of salts turned out to be $0.005 \mathrm{~mol} \%$. $\mathrm{cm}$ (Fig. 4). This enables to evaluate concentration of $\mathrm{SO}_{4}{ }^{2-}$ ions the most harmful impurity in the $\mathrm{KBr}$ salt. The minimal concentration of $\mathrm{SO}_{4}{ }^{2-}$ ions determined by this method depends on the error of readings of the IR spectrophotometer transmission level and maximum possible pellet thickness. In this case, for the pellet thickness $0.25 \mathrm{~cm}$ it

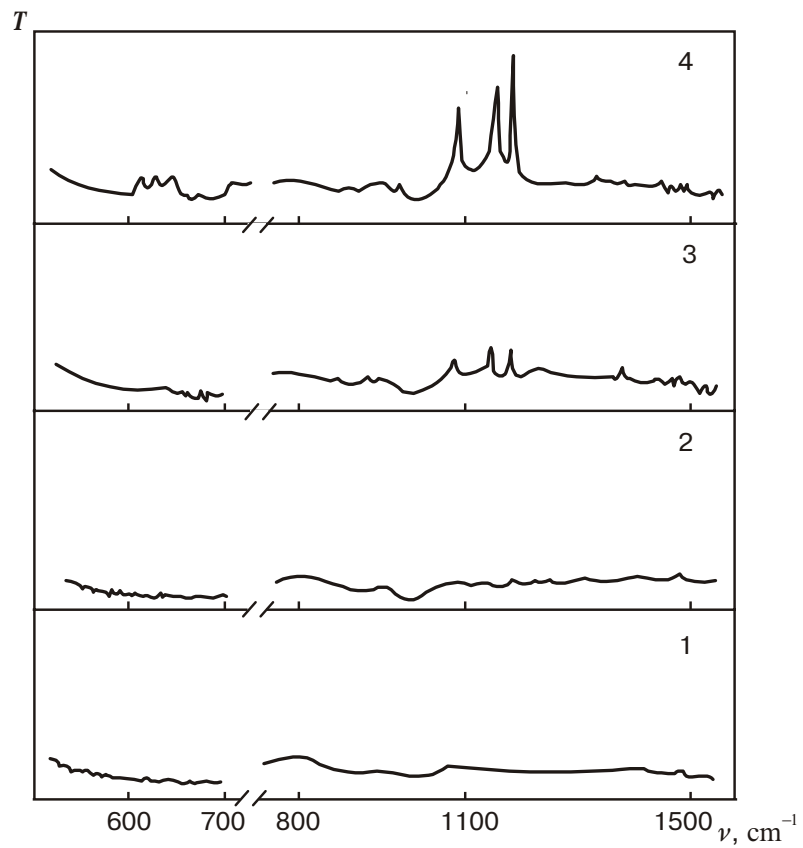

Fig. 2. IR spectra with different structure of $\mathrm{SO}_{4}{ }^{2-}$ absorption bands of $\mathrm{KBr}$ crystals grown from the salts shown in Fig. 1 (curves 1-4, respectively). Content of $\mathrm{M}^{2+}-$ ions: 4. $\mathrm{Ba}^{2+}-1 \cdot 10^{-3}, \mathrm{Ca}^{2+}$ $5 \cdot 10^{-5}, \mathrm{Mg}^{2+}<1 \cdot 10^{-5}, \mathrm{~Pb}^{2+}-1 \cdot 10^{-5}$ mass $\%$. 


\section{V.I. Goriletsky et al.: IR spectroscopy of $\mathrm{KBr}$ salt and crystals}

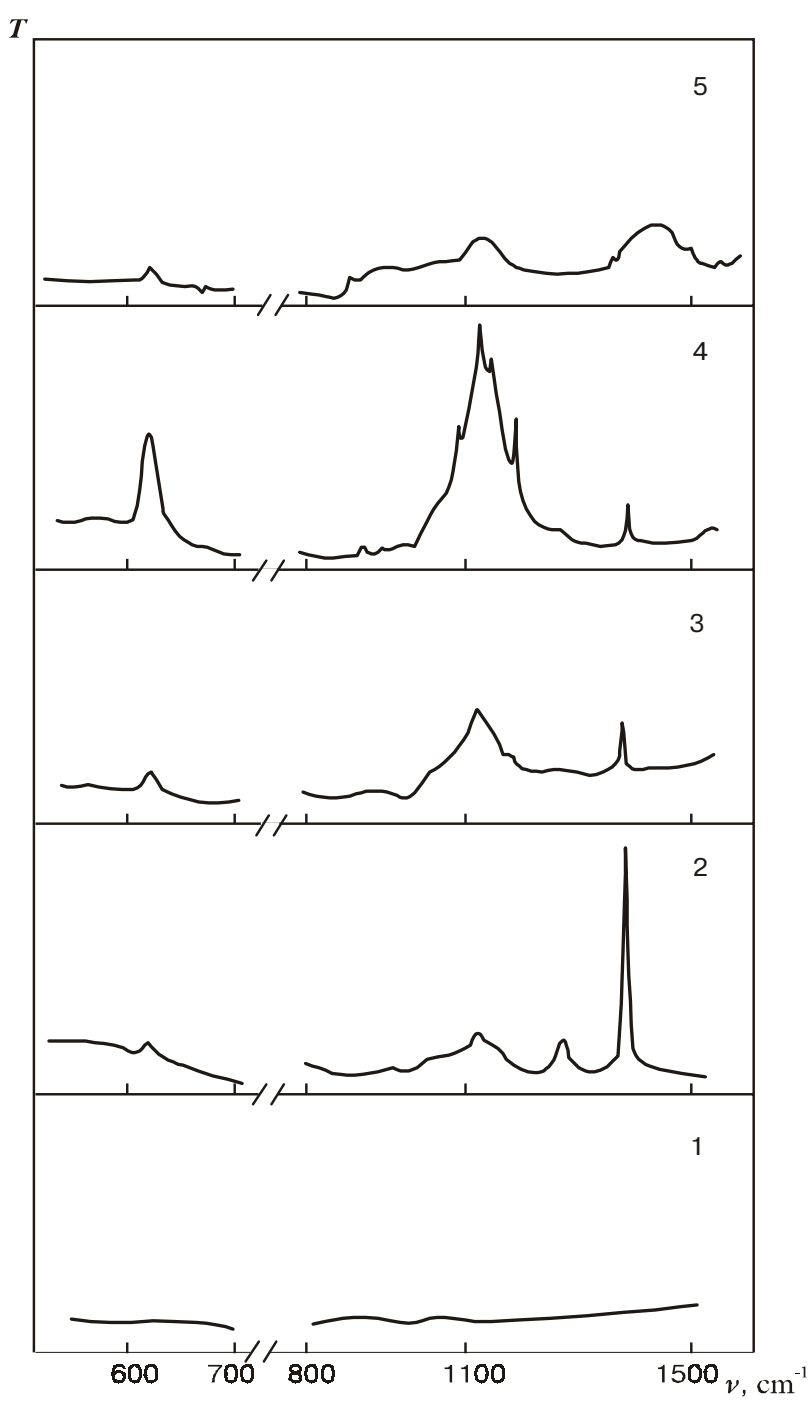

Fig. 3. Absorption bands of water $\left(v_{2}\right.$ and $\left.v_{3}\right)$ in the IR spectra of samles with different content of sodium: $1-2.6 \cdot 10^{-2} \operatorname{mass} \%, d=$ $0.105 \mathrm{~cm} ; 2-6 \cdot 10^{-2} \operatorname{mass} \%, d=0.11 \mathrm{~cm} ; 3-9 \cdot 10^{-2} \operatorname{mass} \%, d=$ $0.10 \mathrm{~cm} ; 4-3.2 \cdot 10^{-2} \operatorname{mass} \%, d=0.35 \mathrm{~cm} ; 5-\mathrm{NaBr} \cdot 2 \mathrm{H}_{2} \mathrm{O}, d=$ $0.12 \mathrm{~cm}$.

is $5 \cdot 10^{-4}$ mol. $\%$. Our experience showed that if in the IR spectrum of the $\mathrm{KBr}$ pellets apart from the unresolved bands of the adsorption water $v_{2}$ and $v_{3}$ there are no absorption bands of other molecular ions (Fig. 1-1), then such salt is suitable for growing optical $\mathrm{KBr}$ crystals.

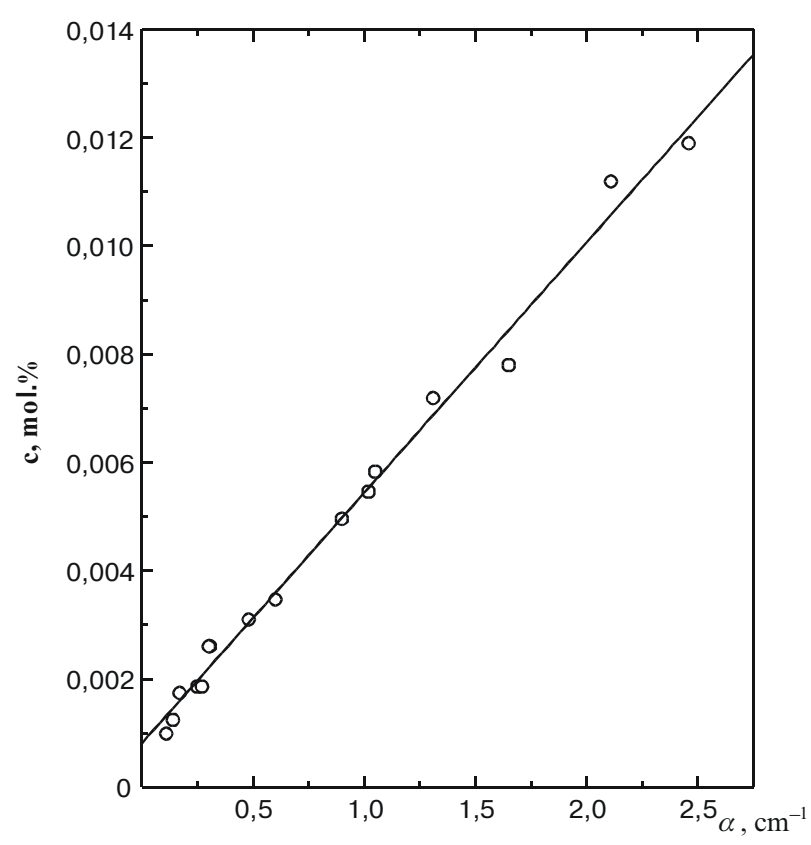

Fig. 4. A linear dependence between the absorption coefficient of $\mathrm{SO}_{4}{ }^{2-}$-ions at $615 \mathrm{~cm}^{-1}\left(k_{1}\right)$ and their concentration $(c)$ in $\mathrm{KBr}$ pellets.

Leveling of the straight line $c=a k_{1}+b$, where $a=0.005 \mathrm{~mol} . \% \cdot \mathrm{cm}$, $b=0.0008$.

\section{Conclusions}

A possibility of an express-control of $\mathrm{KBr}$ salt quality (for growing optical crystals) using the analysis of the IR spectra of these salt pellets has been proved in this paper. The speed, absence of a chemical part of sample preparation and small necessary amounts of the sample are the main advantages of this method of analysis as compared to other physical-and-chemical methods [7].

\section{References}

1. K. Nakamoto, Infrared spectra of inorganic and coordination compounds, M., 1966 (in Russian).

2. G.V. Yukhnevich //Uspekhi khimii, 32, p.1397 (1963) (in Russian).

3. V.V. Boiko, I.Ya. Kushnirenko, G.M. Pentsak, Ukr. Phiz. Zhurn, 22, pp. 1630-1637 (1977).

4. J.C. Deciuus, E.h. Coker, G.I. Brenna // Spectrochem. Acta, 19, p. 1281 (1963).

5. Yu.R. Zakis, V.P. Zeikats, Methods of the analysis of alkali and alkali-earth high purity metal halides. Part 1, Kharkov, Inst. for Single Cryst., pp. 68-78 (1971) (in Russian).

6. A.B. Blank, A.Ya. Nikolenko, L.P. Sukhomlinova, Methods of the analysis of alkali and alkali-earth high purity metal halides. Part 2, Kharkov, Inst. for Single Cryst., pp. 167-175 (1971) (in Russian).

7. D.F. Boltz, Colorimetric determination of nonmetals. INC, New York, London, 1958. 